\title{
No contexto da travessia para o ambiente de trabalho: treinamento de habilidades sociais com universitários
}

\author{
Almir Del Prette \\ Zilda A. P. Del Prette \\ Universidade Federal de São Carlos
}

\begin{abstract}
Resumo
Com base nos atuais desafios inerentes à inserção no mercado de trabalho e a crescente valorização da competência para as relações interpessoais nesse contexto, descreve-se um programa de treinamento de habilidades sociais conduzido em um grupo formado por dez universitários em fase final de graduação na área de ciências exatas. O programa, com delineamento A-B-A, teve uma duração de trinta e seis horas, em duas sessões semanais de aproximadamente duas horas cada e foi planejado em módulos teórico e prático, que ocorriam em uma mesma sessão. A avaliação da intervenção foi realizada por meio da aplicação de um inventário tipo auto-relato (IHS-Del-Prette) antes e depois da intervenção e da avaliação por pares ao final do programa. Os resultados indicaram diferenças significativas (teste de Wilcoxon) entre os escores pré e pósintervenção para a maioria dos participantes e avaliações positivas dos colegas com relação a tais mudanças.
\end{abstract}

Palavras-chave: treinamento de habilidades sociais; relações interpessoais no trabalho; competência social; formação profissional

\begin{abstract}
On the crossing for the work context: social skills training with undergraduate students. Considering the current challenges concerning the insertion in the work context and the growing valorization of the interpersonal competence by employers, this paper describes a group program of social skills training with ten undergraduates attending the final stages of their courses, all in the area of exact sciences. The program, with A-B-A design, lasted thirty-six hours, with two weekly sessions of about two hours each. The whole program was planned in theoretical and practical modules, both occurring in a single session. The program was evaluated with the application of a self-report inventory (HIS-Del-Prette) before and after the intervention and with a peer evaluation at the final session. The results indicated significant differences (Wilcoxon test) between the first and final intervention scores for most of the participants with peer positive evaluations about these changes.
\end{abstract}

Key words: social skills training; interpersonal relationships at work; social competence; professional preparation

A s várias mudanças que ocorrem hoje no mundo do trabalho não podem ser traduzidas apenas e tão somente em termos da economia e das ciências da administração e da produção. Não se pode esquecer, igualmente, que a globalização da economia e o novo liberalismo, por um lado, e o esvanecimento das utopias e enfraquecimento dos movimentos operários, por outro, fortaleceram grandemente o capital (Forrester, 1981). Isso não obstante, o capital não pode ser entendido em uma visão monolítica. Pelo menos duas categorias gerais se contrapõem: o capital especulativo e o capital produtivo.
Independente do foco do olhar que se dirige ao trabalho, percebe-se que essas mudanças extraordinárias afetaram todos os fatores ligados à formação profissional. Dentre os vários aspectos da formação no terceiro grau, interessa-nos, nesse estudo, as demandas (maximizadas) de relações interpessoais no trabalho. Como dissemos em outro estudo: "os novos paradigmas organizacionais que orientam a reestruturação produtiva têm priorizado processos de trabalho que remetem, diretamente, à natureza e à qualidade das relações interpessoais” (Del Prette, A. \& Del Prette, Z., 2001, p. 57). 
Observa-se que, de certa maneira, as várias instâncias de formação profissional (segundo e terceiro graus, principalmente) não acompanharam as demandas do trabalho, em especial no que diz respeito às novas formas de relacionamento humano. No entanto, atualmente pode-se constatar uma tentativa de aproximação da educação para a formação profissional com o mundo do trabalho. A maioria das universidades procura estruturar atividades teóricopráticas de maneira ativa e criativa, por intermédio da organização de setores como, por exemplo, empresas “júnior”, núcleos de formação de cooperativas, programas de formação continuada, mestrados profissionalizantes, extensão universidade-empresa, etc., que, até algum tempo atrás, estavam apenas nos projetos.

Diferentemente do que ocorria há alguns anos, hoje os universitários precisam se preparar para um mercado de trabalho restrito, extremamente exigente, marcado por mudanças rápidas quanto à formação técnica e, igualmente, quanto às habilidades interativas (Associação Brasileira de Treinamento e Desenvolvimento, 1995). Essa transição, do ambiente universitário para o do trabalho, não se constitui uma travessia propriamente tranqüila para a grande maioria dos estudantes, mesmo nas áreas nas quais a demanda por profissionais ainda é razoavelmente alta.

A importância de competências gerais e específicas (inclusive interpessoais) na formação de terceiro grau vem sendo melhor explicitada em nosso meio a partir das exigências de definição das diretrizes curriculares nacionais para os cursos de graduação (MEC, 2001). Antes mesmo dessa exigência, já defendíamos que a formação profissional de terceiro grau deveria articular a competência técnica à social (Del Prette, 1978; Del Prette \& Del Prette, 1996a, b). É altamente defensável que a formação de terceiro grau tenha como escopo, respeitadas as especificidades dos diferentes cursos, pelo menos três classes gerais de capacitação, a saber: (1) capacidade analítica: conjunto de habilidades cognitivas e meta-cognitivas que implicam o raciocínio, o pensamento crítico, o domínio de conhecimentos teóricos específicos a um determinado campo e áreas afins, bem como habilidade de lidar com a automotivação para aprender, resolver problemas e tomar decisões, procurar e organizar informações; (2) capacidade instrumental: domínio das técnicas específicas que caracterizam o exercício da atividade profissional, incluindo as habilidades de produção de conhecimento na área, por exemplo, a experimentação; e (3) competência social: conjunto de desempenhos sociais que atende às diferentes demandas próprias dos vários contextos de trabalho, embora não circunscritas a estes.

Conquanto objeto de preocupação de professores e coordenadores de cursos na universidade e de executivos supervisores de treinamento, nas organizações de trabalho, a competência social não tem sido, geralmente, abordada de maneira sistemática, permanecendo como um subproduto desejável, porém nem sempre alcançado pela maioria dos estudantes e trabalhadores.

Uma área da Psicologia que vêm sistematicamente buscando atender essa demanda de formação profissional, na dimensão do desempenho social, é a do Treinamento de Habilidades Sociais (THS). Os programas de habilidades sociais, voltados para o treinamento e a profilaxia vêm se tornando uma alternativa promissora em nosso meio (Del Prette \& Del Prette, 1999, 2001). Nesse sentido, a literatura científica nacional tem registrado um crescente número de estudos de avaliação (por exemplo, Ayres, 1994; Bandeira, Costa, Del Prette, Del Prette, \& Gerk-Carneiro, 2000; Del Prette, 1978; Del Prette \& Del Prette, 1983; Del Prette, Del Prette, \& Barreto, 1999; Del Prette, Del Prette, \& Castelo Branco, 1992; Falcone, 1998; Gerk-Carneiro, Dias, Nyaradi, \& Aquino, 2000; Pasquali \& Gouveia, 1990).

O THS tem uma longa tradição como método de intervenção, desde os estudos iniciais de Argyle e sua equipe em Oxford (ver principalmente Argyle, 1967/1994; Argyle, Bryant, \& Trower 1974; Argyle \& Kendon, 1967; Trower, Bryant, \& Argyle, 1978), seguidos à contribuição americana e canadense. Nesse caso, podem ser lembrados: a) os estudos pioneiros de Zigler e Phillips (1960, 1961, 1962), na avaliação de habilidades sociais com pacientes psiquiátricos hospitalizados; b) a proposta de programa denominada Efetividade Interpessoal, de Liberman e seu grupo (Liberman, King, DeRise, \& McCann, 1975); c) os programas desenvolvidos com pacientes esquizofrênicos (Liberman, 1982; Wallace, \& Liberman, 1985; Wallace, Nelson, \& Liberman, 1980); d) as análises teóricas que trouxeram novos aprofundamentos ao campo (em especial, Bellack, 1979; Curran, 1979; McFall, 1982).

A partir da década de 80, houve um aumento crescente de publicações de programas de intervenção em habilidades sociais. É interessante registrar que ocorreu, também, um aumento significativo de estudos teóricos ampliando o quadro conceitual da área (ver, entre outros, Bedell \& Lennox, 1997; Segrin, 1993; Trower, 1995) que, entre outras questões examinadas, defendiam a necessidade de uma teoria geral do relacionamento interpessoal e a estruturação de um sistema de classificação de habilidades sociais.

A adaptação do método do Treinamento de Habilidades Sociais, do setting clínico para ambientes escolares e de trabalho, não é propriamente uma novidade na área. Argyle, há mais de vinte anos, propôs a inclusão do THS no treinamento de profissionais, definindo algumas classes de habilidades sociais relacionadas a diferentes tipos de atividades como vendas, ensino e psicoterapia (Argyle, 1967/ 1994, 1980).

No Brasil, os programas não terapêuticos de Treinamento de Habilidades Sociais, à exceção dos programas com jovens desempregados (Del Prette, 1995; Sarriera, Meira, Berlim, Bem, \& Câmara, 1999) vêm sendo realizados principalmente com universitários de Psicologia (Del Prette, 1978; Del Prette \& Del Prette, 1983; Del Prette, Del Prette, \& Barreto, 1999; Falcone, 1998). Estes estudos partem do pressuposto de que a aprendizagem de habilidades sociais não está inserida entre os objetivos das disciplinas e que um número considerável de alunos pode apresentar dificuldades ou déficits no relacionamento interpessoal (Abarca \& Hidalgo, 1989; Bryant \& Trower, 1974; Del Prette, Del Prette, \& Correia, 1992). 
Teoricamente, portanto, esses alunos precisariam desse treinamento para completar a sua formação acadêmica.

Esses pressupostos nortearam o atendimento ao pedido de um grupo de alunos que cursava o último período de graduação na Universidade de São Paulo (USP - São Carlos), para a realização de um Programa de Treinamento de Habilidades Sociais, tendo como primeiro objetivo, definido pelos alunos, "uma ajuda que os qualificasse para vencer as dificuldades de obtenção de emprego". Para eles, o fato de estarem terminando cursos reconhecidamente bem avaliados, em universidade de grande prestígio, não era suficiente, uma vez que "necessitavam de habilidades sociais e emocionais" para serem avaliados positivamente nas provas de seleção, que não “focalizavam apenas conhecimentos técnicos”, segundo suas palavras.

O presente artigo tem como objetivo descrever a aplicação, o formato e os resultados de um programa de THS com um grupo de universitários, sob um delineamento A-B-A, visando a promoção de habilidades sociais para a inserção no mercado trabalho.

\section{Método}

\section{Participantes}

Participaram do programa dez universitários que cursavam o último período de cursos de graduação em Ciências Exatas: Engenharia de Produção (6), Engenharia Elétrica (2), Ciência de Computação (1) e Engenharia Mecânica (1). A média de idade do grupo era de 24,7 anos, um deles era casado e somente um pertencia ao sexo feminino.

\section{Características e aplicação do programa de intervenção}

Contato prévio e contrato. Inicialmente, foi realizada uma reunião informal com os interessados com objetivos de: (1) explicitar o conteúdo, formato e aspectos éticos do programa; (2) realizar um levantamento de objetivos ou expectativas gerais e particulares registrados pelos participantes em uma folha sulfite, contendo a indicação do nome, idade e curso; (3) estabelecer um contrato de prestação de serviço; e (4) definir duração, horários, local e equipamentos a serem utilizados (retroprojetor, televisão e vídeo cassete).

O programa de intervenção. O Programa de Desenvolvimento Interpessoal Profissional-USP (PRODIPUSP, como foi denominado para efeito de contrato) foi planejado para ser desenvolvido em 17 sessões, com atividades teóricas e práticas. A parte teórica consistiu de exposições dialogadas, complementadas por atividades realizadas em grupo. Na parte prática, foram utilizadas vivências, com arranjo de situações para desempenhos de papéis prováveis de serem requeridos aos participantes no período de estágio profissionalizante, de procura de emprego, e de atuação em uma empresa, já como contratado. As sessões ocorreram duas vezes por semana, com a duração de duas horas cada e foram realizadas na própria Universidade, em uma sala isolada e espaçosa o suficiente para permitir a movimentação requerida nas vivências.

O programa foi conduzido por dois facilitadores simultaneamente. Quando um facilitador coordenava, o outro se mantinha atento, observando e intervindo apenas quando julgava necessário. A divisão de tarefas de coordenação era realizada previamente conforme a familiaridade dos facilitadores com os vários tipos de atividades a serem desenvolvidas no grupo

Organização das sessões. As sessões foram planejadas tendo os objetivos distribuídos ao longo do programa em uma seqüência de menor para maior complexidade. Nas sessões iniciais foram incluídas, como objetivos do treinamento, habilidades tais como as de observar, registrar, interpretar, relacionar comportamentos a eventos antecedentes e conseqüentes, identificar articulações entre comportamento, sentimento e pensamento etc., consideradas componentes de outras mais amplas em situação de trabalho. As sessões intermediárias envolveram as habilidades de expressar sentimentos e empatia, prover feedback, elogiar e aceitar elogios, iniciar e manter conversação, abordar pessoas de autoridade, etc. As sessões finais do programa objetivaram a aprendizagem de habilidades de aceitar, fazer e rebater críticas, coordenar grupos de trabalho, falar em público defendendo projetos, expor e defender as próprias idéias em reuniões de equipe e com diretores, etc. Em todas as sessões foram enfatizadas as habilidades de identificar comportamentos verbais e não-verbais, prover feedback e expressar opiniões e sentimentos, consideradas como parte das habilidades de processo (Del Prette, Z., \& Del Prette, A., 2001).

Características das sessões e procedimento utilizados. Com exclusão da primeira sessão e da última, destinadas à avaliação, as demais podem ser caracterizadas como segue.

As primeiras cinco sessões foram divididas em três partes. A parte inicial constava de breve exposição de um tema pelos facilitadores, como: "relações entre emoção, pensamento e comportamento”, “comunicação verbal e não-verbal”, "feedback", "resolução de problema e tomada de decisão", incluindo vivências pertinentes aos temas, com ênfase, em sua maioria, nos vários tipos de relacionamento do ambiente de trabalho. A parte intermediária incluía discussões, em pequenos grupos, de questões relativas aos temas abordados. Na parte final, era realizada a avaliação geral da sessão e atribuição de tarefas de casa (da terceira sessão em diante).

A partir da sexta sessão, as exposições raramente ocorreram, iniciando-se, então, pelo relato das tarefas e/ou experiências relacionadas às atividades dos participantes. Seguia-se a aplicação de vivências apropriadas aos objetivos e, igualmente, procedimentos específicos destinados a suprir déficits de habilidades.

As últimas sessões do programa caracterizaram-se por uma redução progressiva das vivências (aplicadas, geralmente no final da sessão) e, em ordem inversa, um 
aumento de procedimentos derivados de técnicas próprias da área do THS tais como: ensaio comportamental, modelação, feedback, instrução, etc.

\section{Instrumentos}

O Inventário de Habilidades Sociais (IHS-Del-Prette). Em sua versão original, o IHS-Del-Prette (Del Prette, Z. \& Del Prette, A., 2001) consiste de 38 itens de situações e reações em que o respondente indica a freqüência com que reage conforme especificado no item. No presente estudo foi aplicada uma versão desse instrumento, usando-se o indicador dificuldade, ao invés de freqüência. Os estudos com o IHSDel-Prette indicaram uma estrutura composta de cinco fatores, que foram utilizados como base para a análise dos dados do presente estudo: Fator 1 - Enfrentamento Com Risco (habilidades assertivas para lidar com situações que demandam a afirmação e defesa de direitos e auto-estima, com risco potencial de rejeição, réplica ou oposição pelo interlocutor); Fator 2 - Auto-Afirmação na Expressão de Afeto Positivo; Fator 3 - Conversação e Desenvoltura Social; Fator 4 - Auto-Exposição a Desconhecidos ou a Situações Novas; e Fator 5 - Autocontrole da Agressividade em Situações Aversivas (agressão, pilhéria, descontrole).

A avaliação por pares. Consistiu de uma ficha com instrução para cada participante registrar, em ordem decrescente, os nomes de três colegas do grupo que obtiveram maior ganho com o treinamento, com exemplos observados das mudanças ocorridas.

\section{Procedimentos de coleta de dados}

A aplicação do IHS-Del-Prette foi realizada na primeira e na última sessão, simultaneamente para todo o grupo. A avaliação por pares foi realizada na última sessão, simultaneamente para todos os participantes. Os relatos de aquisições durante o programa foram registrados pelos facilitadores.

\section{Tratamento de dados}

O levantamento de objetivos e expectativas foi utilizado para o planejamento, mais do que para a avaliação do programa, e para orientação de alguns procedimentos e esclarecimento quanto a possibilidade de serem incluídos, ou não, no programa.

Os dados obtidos com o IHS-Del-Prette, nesta versão para dificuldade, foram organizados em planilhas, computando-se os escores de cada participante e também os escores fatoriais, tomando-se como base os itens de cada fator identificado na versão original, que avaliava freqüência.

Além dos escores, foram computados os valores médios de cada item nas avaliações pré e pós-intervenção. Com base no escore geral e nos escores fatoriais, realizou-se um tratamento estatístico (Wilcoxon) das diferenças entre os valores obtidos nas avaliações pré e pós-intervenção.

Com relação à avaliação por pares, procedeu-se uma ordenação com base na freqüência com que os participantes foram indicados pelos demais.

\section{Resultados e discussão}

Os resultados obtidos pela análise estatística dos indicadores de dificuldade pré e pós-intervenção, em termos do escore geral e dos escores fatoriais dos itens do IHS-DelPrette, são apresentados na Tabela 1.

Como se vê na Tabela 1, os valores médios do grupo, no pós-teste, em termos de dificuldade, foram significativamente

Tabela 1

Dados estatísticos de mudanças verificadas no escore geral e nos escores fatoriais entre o pré e o pós -teste (Wilcoxon signed ranks test, $n=10$ )

\begin{tabular}{|c|c|c|c|c|c|}
\hline Indicador & momento & média & $\begin{array}{l}\text { desvio- } \\
\text { padrão }\end{array}$ & $z$ & $p$ \\
\hline \multirow[t]{2}{*}{ Escore } & Pré & 60,60 & 20,559 & \multirow{2}{*}{$-2,703$} & \multirow{2}{*}{0,007} \\
\hline & Pós & 40,00 & 18,797 & & \\
\hline \multirow{2}{*}{$\begin{array}{l}\text { F1 - Enfrentamento e Auto-afirmação } \\
\text { com Risco }\end{array}$} & Pré & 18,90 & 7,031 & \multirow{2}{*}{$-2,552$} & \multirow{2}{*}{0,011} \\
\hline & Pós & 13,00 & 6,074 & & \\
\hline \multirow[t]{2}{*}{ F2 - Expressão de Afeto Positivo } & Pré & 9,10 & 3,178 & \multirow{2}{*}{$-2,670$} & \multirow{2}{*}{0,008} \\
\hline & Pós & 4,50 & 4,197 & & \\
\hline \multirow[t]{2}{*}{ F3 - Conversação e Desenvoltura Social } & Pré & 11,90 & 3,784 & \multirow{2}{*}{$-2,199$} & \multirow{2}{*}{0,028} \\
\hline & Pós & 8,40 & 3,978 & & \\
\hline \multirow[t]{2}{*}{ F4 - Auto-exposição a Desconhecidos } & Pré & 4,90 & 3,573 & \multirow{2}{*}{$-1,131$} & \multirow{2}{*}{0,258} \\
\hline & Pós & 3,80 & 1,989 & & \\
\hline \multirow[t]{2}{*}{ F5 - Autocontrole de Agressividade } & Pré & 4,30 & 2,830 & \multirow{2}{*}{$-2,588$} & \multirow{2}{*}{0,010} \\
\hline & Pós & 2,70 & 1,767 & & \\
\hline
\end{tabular}


mais baixos que os do pré-teste no escore geral e nos três primeiros fatores. Em outras palavras, pode-se afirmar que os participantes relataram emitir, com menor dificuldade, o conjunto das habilidades avaliadas e, em particular, aquelas referentes aos fatores 1, 2, 3 e 5. Com relação ao Fator 4 Auto-Exposição a Desconhecidos e Situações Novas -, apesar de não atingir significância, o valor médio do grupo foi menor na pós-intervenção, mostrando que, pelo menos para alguns participantes, houve uma redução de dificuldade que, considerando o desvio-padrão, tornou a amostra mais homogênea.

Uma análise do desempenho de cada participante nesses indicadores é apresentada na Figura 1, com dados relativos ao escore geral.

O escore total de dificuldade podia variar entre zero e 152. Os participantes apresentaram um escore médio inicial já inferior ao ponto médio da variação possível (que seria 76) e, mesmo assim houve ainda uma redução para 40. Pode-se verificar, ainda, que essa redução ocorreu para todos os participantes, exceto para P5.

Uma análise do desempenho dos participantes em cada um dos fatores é apresentada na Tabela 2 .

Como se vê na Tabela 2, a maioria dos participantes apresentou o mesmo escore, ou apresentou escores mais baixos na avaliação efetuada ao final do programa. A exceção foi P5, que apresentou valores mais altos em três dos fatores (F1, F3 e F4). Teoricamente, haveria duas explicações possíveis para o aumento de valores na segunda avaliação, em programa com população não-clínica. A primeira poderia se relacionar à ansiedade devido à evocação de situações de desempenho trazidas pelo inventário, muito mais acentuada na segunda avaliação do que na primeira, quando a preocupação com a competência era menor. A segunda, diz respeito a uma maior acuracidade de observação e autoobservação desenvolvida no treinamento e, conseqüentemente, uma alteração da autopercepção, mesmo quando o participante se expõe pouco a treinamento específico de suas dificuldades. No caso de P5, a metodologia do programa, através de vivências, minimiza a possibilidade de aumento da ansiedade, tornando menos provável a primeira

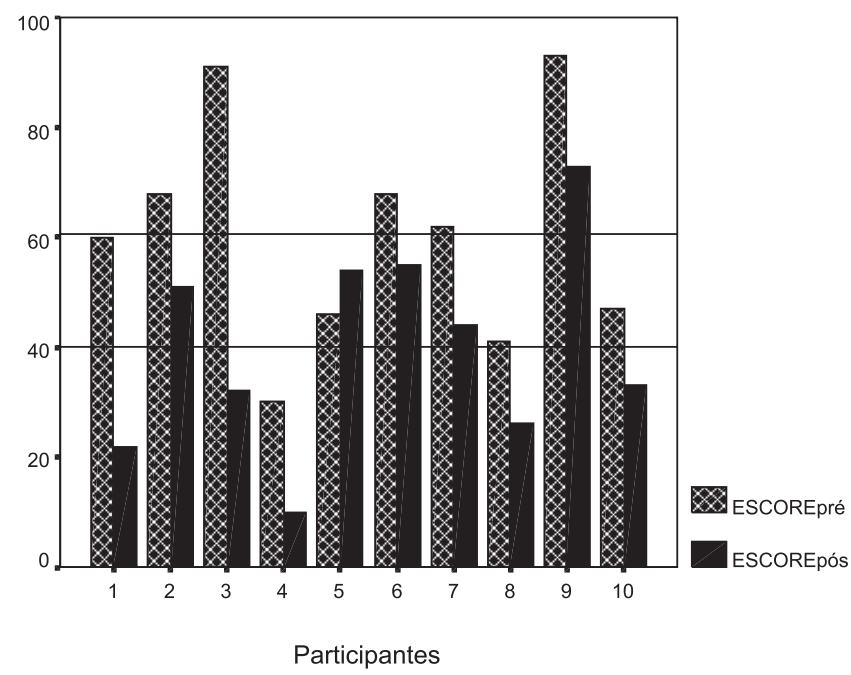

Figura 1. Escores gerais de dificuldade de cada um dos participantes, nas avaliações pré e pós-intervenção com o IHS-Del-Prette.

Tabela 2

Escores fatoriais de cada um dos participantes nas avaliações pré e pós -intervenção

\begin{tabular}{|c|c|c|c|c|c|c|c|c|c|c|}
\hline \multirow[t]{2}{*}{ Participante } & \multicolumn{2}{|c|}{ F1 } & \multicolumn{2}{|c|}{$\mathrm{F} 2$} & \multicolumn{2}{|c|}{ F3 } & \multicolumn{2}{|c|}{ F4 } & \multicolumn{2}{|c|}{ F5 } \\
\hline & Pré & Pós & Pré & Pós & Pré & Pós & Pré & Pós & Pré & Pós \\
\hline P1 & 17 & 5 & 11 & 3 & 12 & 4 & 5 & 2 & 3 & 2 \\
\hline $\mathrm{P} 2$ & 23 & 17 & 15 & 12 & 11 & 8 & 5 & 5 & 4 & 2 \\
\hline P3 & 28 & 11 & 9 & 0 & 16 & 6 & 10 & 4 & 11 & 4 \\
\hline P4 & 4 & 2 & 9 & 0 & 8 & 4 & 0 & 2 & 3 & 1 \\
\hline P5 & 15 & 17 & 8 & 7 & 8 & 11 & 1 & 5 & 5 & 5 \\
\hline P6 & 21 & 20 & 8 & 8 & 14 & 12 & 8 & 4 & 4 & 3 \\
\hline P7 & 22 & 15 & 5 & 3 & 14 & 11 & 7 & 5 & 2 & 2 \\
\hline P8 & 14 & 10 & 8 & 1 & 6 & 7 & 1 & 0 & 2 & 1 \\
\hline P9 & 27 & 20 & 13 & 9 & 18 & 16 & 9 & 7 & 7 & 6 \\
\hline P10 & 18 & 13 & 5 & 2 & 12 & 5 & 3 & 4 & 2 & 1 \\
\hline
\end{tabular}


hipótese. Como P5 foi o participante que menos se expôs a treinamento específico, a segunda hipótese é mais pertinente. A aprendizagem observacional constitui um fator importante no treinamento, garantindo aquisições, tanto em termos de percepção do próprio desempenho e do desempenho dos demais quanto da aprendizagem de novas habilidades, embora isso não ocorra linearmente, variando de pessoa para pessoa. É provável que P5 tenha adquirido uma percepção mais acurada sobre suas dificuldades, mas a observação não tenha sido suficiente para superá-las. Em outras palavras, os ganhos do programa precisam ser bastante salientes para que ocorram diferenças entre as avaliações pré e pós-intervenção.

Uma análise mais detalhada dos resultados, em termos dos valores médios de dificuldade do grupo para cada um dos itens do IHS-Del-Prette, é apresentada na Figura 2, dispondo-se em ordem decrescente os valores obtidos na avaliação pré-intervenção.

Como se vê na Figura 2, de um modo geral os participantes já indicavam, no início do treinamento, um valor médio inicial (média $=1,64$; desvio-padrão $=1,07$ ) abaixo do ponto médio da escala (“2”). Ainda assim, ocorreu uma redução desse valor na segunda avaliação (média $=0,67$; desvio-padrão = 0,48). Esses dados são bastante expressivos de um efeito positivo do programa.

Examinando-se em quais itens houve maior redução, verifica-se que isto ocorreu principalmente nos de maior dificuldade inicial, o que confere relevância à intervenção. Entre esses itens encontravam-se alguns particularmente importantes no contexto de trabalho, por fazerem parte de outros desempenhos sociais mais complexos requeridos nesse ambiente. Entre essas habilidades se incluem: conversar em grupo de desconhecidos (1), interromper conversa ao telefone (24), apresentar-se a alguém (7), cumprimentar desconhecidos (31), lidar com críticas (18), participar de conversação (8), elogiar quem faz algo de bom (6) fazer pergunta a desconhecidos (23), fazer perguntas na escola ou no trabalho (29) e pedir favor a colega (37).

Um outro subconjunto de habilidades, em que foi relatada a redução de dificuldade, não possui, em sua maioria, uma grande demanda no contexto de trabalho. No entanto, é defensável o argumento de que dificuldades ou déficits nessas habilidades podem afetar o rendimento profissional, devido à sua influência sobre a vida afetiva do indivíduo (Argyle, 1980). Entre tais habilidades, pode-se citar: expressar desagrado a amigo (27), romper relacionamento (25), elogiar familiares (28), cobrar dívida de amigo (5), expressar carinho a familiares (10), expressar felicidade a amigos (35), e expressar desagrado a familiares (15).

Em resumo, os dados da análise dos itens do IHS-DelPrette indicaram redução da dificuldade em habilidades requeridas no contexto de trabalho e também em outras que, se deficitárias, poderiam afetar, indiretamente, o desempenho profissional.

Na avaliação final por pares, os participantes citados entre os que mais apresentaram melhoras no desenvolvimento interpessoal foram: P6 (por oito colegas), P1 (por sete colegas) e P3 (por seis colegas). Além disso, P4 recebeu três citações, P8 e P9 duas e P2 e P7 uma citação. Comparando-se esses

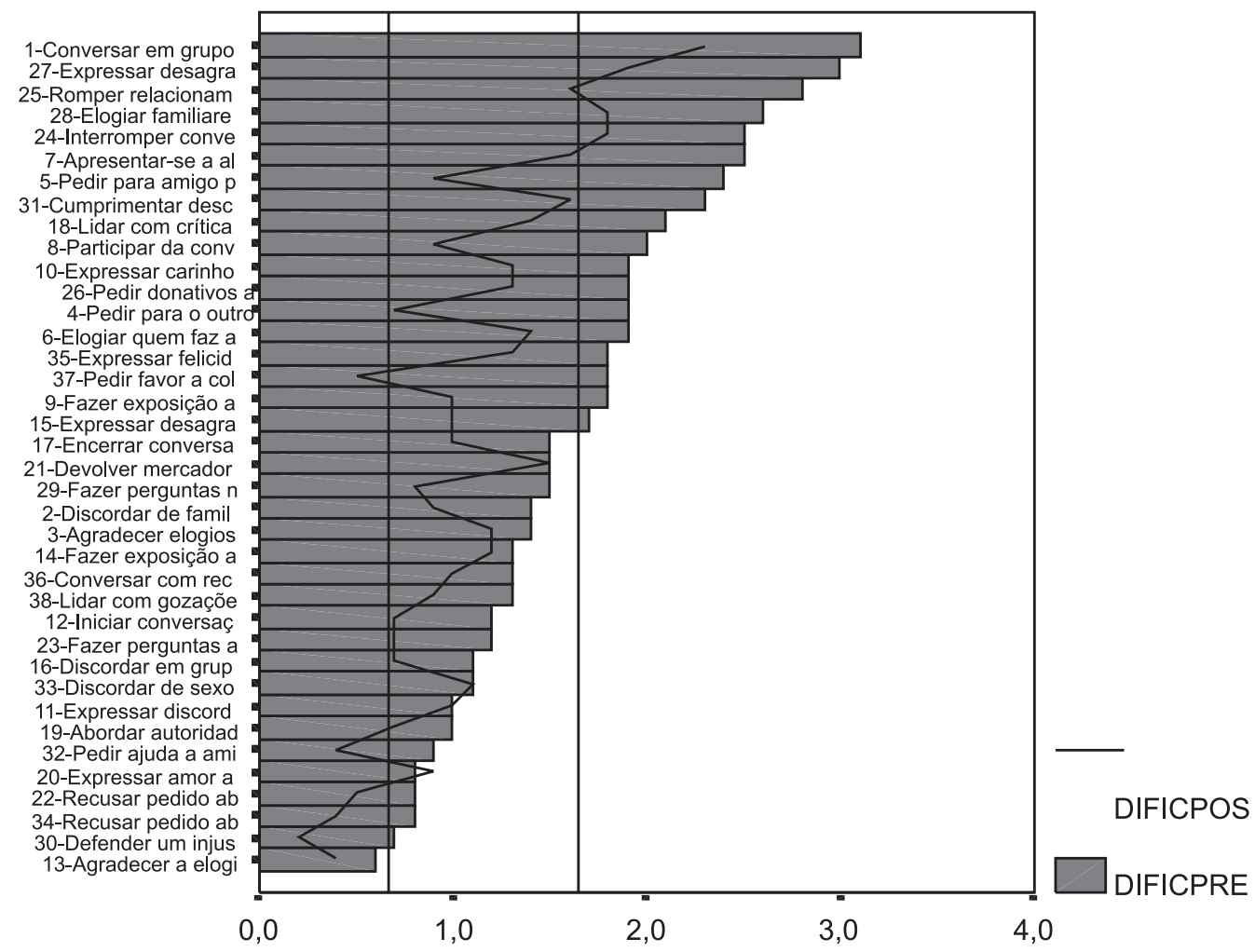

Figura 2. Valores médios de dificuldade relatados pelos participantes nos itens do IHS-DelPrette antes e depois da intervenção. 
dados com os da Figura 1, vê-se que houve, em linhas gerais, uma correspondência entre a auto-avaliação no IHS-Del-Prette e a avaliação dos pares para a maioria dos participantes.

Além desses indicadores quantitativos, ocorreram vários relatos orais de melhora e aplicação dos resultados do treinamento, ao longo de praticamente todas as sessões. São apresentados abaixo alguns depoimentos espontâneos, escritos na última sessão, que também permitem aferir a percepção dos participantes quanto às próprias mudanças alcançadas:

Melhorei bastante, acima de 100\% (P1).

Acredito que tive uma melhora de $40 \%$. Posso me incluir entre os que mais melhoraram (P2). Houve pontos em que acho ter piorado em função de algumas situações que não tinha vivenciado e achava que meu desempenho era melhor, e outros em que melhorei. No todo, digo que melhorei, os colegas que fizeram o curso me ajudaram muito (P5).

Pessoalmente me vejo com uma melhora bastante expressiva, principalmente com relação à recusa de pedidos abusivos e assertividade em geral (P7).

Tive uma melhora significativa em minhas habilidades (P10).

\section{Conclusão}

Pode-se dizer que o PRODIP-USP foi efetivo na maioria dos objetivos a que se propôs. Os participantes alcançaram, durante o treinamento, uma compreensão básica dos conceitos e de aspectos teóricos da área das Habilidades Sociais. Além disso, as observações dos desempenhos durante as vivências mostraram o desenvolvimento e aprimoramento de habilidades de processo, tais como observação e descrição de comportamentos, a leitura do ambiente social e a automonitoria do desempenho em situações que exigem criatividade e autocontrole. Observouse também, em situações de vivência, a aquisição das habilidades de dar e receber feedback, elogiar desempenhos, expressar-se de forma assertiva e empática e lidar com críticas (aceitar, rejeitar, fazer).

Alguns participantes relataram o uso das habilidades desenvolvidas em situação de treinamento para outras situações como as de família, trabalho, acadêmicas, de namoro etc. Adicionalmente, passaram a utilizar, em suas conversações, conforme relato e observação em sessão, termos próprios da área, tais como assertividade, comunicação empática, comportamento opositivo, modelação, etc. A adequação desse uso reflete uma aquisição de conceitos que pode ter influenciado na prática das habilidades recémadquiridas.

A análise do PRODIP-USP suscita algumas questões empíricas. Uma questão que parece bastante pertinente consiste na avaliação do formato do programa teórico-prático versus prático. O mais usual, na tradição da área do THS, consiste na utilização de procedimentos dirigidos para a aquisição de habilidades deficitárias no repertório de desempenhos sociais (ver, entre outros, Ogilvy, 1994; Reed,
1994; Speas, 1979), não se incluindo considerações teóricas, a não ser aquelas exclusivamente pertinentes às habilidades cognitivas.

O formato utilizado no PRODIP-USP, teve como base a suposição de que: a) a população não-clínica, em particular a universitária, requer um maior detalhamento teórico (entender os fundamentos para aplicá-los); b) algumas das explicações teóricas, por exemplo, sobre os mecanismos de aprendizagem, auxiliam na aquisição de habilidades sociais (aprendizagem antes do desempenho, ver Bandura, 1977, 1986). De qualquer maneira, essas considerações também se constituem especulações a serem examinadas empiricamente.

Além dessas considerações, o presente trabalho mostra a importância do desenvolvimento de habilidades sociais, em especial aquelas que respondem às demandas da transição entre o ambiente universitário e o mercado de trabalho. De um modo geral, o ensino, no contexto educacional brasileiro, enfatiza a capacitação analítica e instrumental, deixando a desejar com relação ao desenvolvimento interpessoal do aluno.

O mercado de trabalho restrito, porém ávido por profissionais bem formados, poderá se constituir em foco de pressão sobre os cursos de graduação no país. Pode-se pensar, portanto, em dois focos de pressão, a interna, provinda dos próprios alunos (como a que originou o presente trabalho) e a externa, diretamente aplicada na seleção dos profissionais socialmente mais competentes, que pode impor demandas de ampliação dos objetivos curriculares de formação acadêmica. Aquelas universidades que mais prontamente responderem a tais pressões certamente estarão dando um passo importante em direção a um processo de educação integral, evitando deixar seus alunos entregues a si mesmos, nessa difícil travessia para o mundo de trabalho.

\section{Referências}

Abarca, N., \& Hidalgo, C. G. (1989). Evaluación psicométrica de habilidades sociais en jóvenes universitarios chilenos. Revista Análisis del Comportamiento, 4, 51-62.

Associação Brasileira de Treinamento e Desenvolvimento - ABTD. (1995). Manual de Treinamento e Desenvolvimento. São Paulo: Makron.

Argyle, M. (1980). The development of applied Social Psychology. In G. Gilmour \& S. Duck (Orgs.), The development of Social Psychology. Londres: Academic.

Argyle, M. (1994). Psicología del comportamiento interpersonal. Madri: Alianza. (Originalmente publicado em 1967)

Argyle, M., \& Kendon, A. (1967). The experimental analysis of social performance. Advances in Experimental Social Psychology, 3, 55-98.

Argyle, M., Bryant, B., \& Trower, P. (1974). Social skills training and psychotherapy: a comparative study. Psychological Medicine, 4, 435-443.

Ayres, L. S. M. (1994). Uma escala brasileira para a medida da assertividade. Dissertação de Mestrado não-publicada, Universidade Gama Filho, Rio de Janeiro.

Bandeira, M., Costa, M. N., Del Prette, Z. A. P., Del Prette, A., \& GerkCarneiro, E. (2000). Qualidades psicométricas do Inventário de Habilidades Sociais (IHS): estudo sobre a estabilidade temporal e a validade concomitante. Estudos de Psicologia, 5, 401-419. 
Bandura, A. (1977). Social learning theory. New Jersey: Prentice-Hall.

Bandura, A. (1986). Social foundations of thought and action: a social cognitive theory. New Jersey: Prentice-Hall.

Bedell, J. R., \& Lennox, S. S. (1997). Handbook for communication and problem-solving skills training: a cognitive-behavioral approach. Nova York: John Wiley \& Sons.

Bellack, A. S. (1979). A critical appraisal of strategies for assessing social skill. Behavioral Assessment, 1, 157-176.

Bryant, B., \& Trower, P. (1974). Social difficulty in a student sample. British Journal of Educational Psychology, 44, 13-21.

Curran, J. (1979). Pandora's box reopened? The assessment of social skills. Journal of Behavioral Assessment, 1, 55-71.

Del Prette, A. (1978). O treino assertivo na formação do psicólogo. Arquivos Brasileiros de Psicologia Aplicada, 30, 53-55.

Del Prette, A. (1995). Treinamento comportamental: uma alternativa de atendimento à população não clínica. Revista de Psicologia, 3, 67-81.

Del Prette, A., \& Del Prette, Z. A. P. (2001). Psicologia das relações interpessoais: vivências para o trabalho em grupo. Petrópolis: Vozes.

Del Prette, A., Del Prette, Z. A. P., \& Castelo Branco, U. V. (1992). Competência social na formação do psicólogo. Paidéia: Cadernos de Educação, 2, 4050.

Del Prette, A., Del Prette, Z. A. P., \& Barreto, M. C. M. (1999). Habilidades sociales en la formación del psicólogo: análisis de un programa de intervención. Psicología Conductual, 7, 27-47.

Del Prette, Z. A. P., \& Del Prette, A. (1983). Análise de repertório assertivo em estudantes de Psicologia. Revista de Psicologia, 1, 15-24.

Del Prette, Z. A. P., \& Del Prette, A. (1996a). Habilidades envolvidas na atuação do psicólogo escolar/educacional. In S. M. Wechsler (Org.), Psicologia Escolar: pesquisa, formação e prática (pp. 139-156). Campinas: Alinea.

Del Prette, Z. A. P., \& Del Prette, A. (1996b). Habilidades sociais: uma área em desenvolvimento. Psicologia: Reflexão e Crítica, 9, 287-309.

Del Prette, Z. A. P., \& Del Prette, A. (1999). Psicologia das habilidades sociais: terapia e educação. Petrópolis: Vozes.

Del Prette, Z. A. P., \& Del Prette, A. (2001). Inventário de Habilidades Sociais (IHS-Del-Prette): manual de aplicação, apuração e interpretação. São Paulo: Casa do Psicólogo.

Del Prette, Z. A. P., Del Prette, A., \& Correia, M. E. B. (1992). Competência social: um estudo comparativo entre alunos de Psicologia, Serviço Social e Engenharia Mecânica. Psicólogo Escolar: Identidade e Perspectivas, 382-384.

Falcone, E. O. (1998). Avaliação de um programa de treinamento de empatia com universitários. Tese de Doutorado não-publicada, Universidade de São Paulo, São Paulo.

Forrester, V. (1981). O horror econômico. São Paulo: Editora da Universidade Estadual Paulista.
Gerk-Carneiro, E. G. P., Dias, R. D., Nyaradi, N. O., \& Aquino, S. M. C. (2000). Habilidades sociais e cognitivas em estudantes universitários brasileiros. Revista Galego Portuguesa de Psicologia e Educação, 6, 689697.

Liberman, R. P. (1982). Assessment of social skills. Schizophrenia Bulletin, 8, 203-212.

Liberman, R. P., King, L. W., DeRisi, W. J., \& McCann, M. (1975). Personal effectiveness. Champaign, Illinois: Research Press.

McFall, R. M. (1982). A review and reformulation of the concept of social skills. Behavioral Assessment, 4, 1-33.

Ministério de Educação e Cultura, Secretaria de Ensino Superior. (2001). Diretrizes curriculares para os cursos de graduação. Obtido em 02.maio.2002, da rede mundial de computadores: http://www.mec.gov.br/ Sesu/diretriz.shtm.

Ogilvy, C. M. (1994). Social skills training with children and adolescents: a review of evidence on effectiveness. Educational Psychology, 14, 73-82.

Pasquali, L., \& Gouveia, V. V. (1990). Escala de Assertividade de Rathus RAS: adaptação brasileira. Psicologia: Teoria e Pesquisa, 6, 233-249.

Reed, M. K. (1994). Social skills training to reduce depression in adolescents. Adolescence,_29, 293-302.

Sarriera J. C., Meira, P. B., Berlim, C. S., Bem, L. A., \& Câmara, S. C. (1999). Treinamento em habilidades sociais na orientação de jovens à procura de emprego. Psico, 1, 67-85.

Segrin, C. (1993). Social skills deficits and psychosocial problems: antecedent, concomitant, or consequent? Journal of Social and Clinical Psychology, 12, 336-353.

Speas, C. M. (1979). Job-seeking interview: A comparison of four instructional techniques. Journal of Counseling Psychology, 26, 405-412.

Trower, P. (1995). Adult social skills: state of the art and future directions. In W. O’Donohue \& L. Krasner (Orgs.), Handbook of psychological skills training: clinical techniques and applications (pp. 54-80). Nova York: Allyn \& Bacon.

Trower, P., Bryant, B., \& Argyle, M. (1978). Social skills and mental health. Londres: Methuen: Pittsburgh University Press.

Wallace, C. J., \& Liberman, R. P. (1985). Social skills training for patients with schizophrenia: a controlled clinical trial. Psychiatry Research, 15, 239-247.

Wallace, C. J., Nelson, C. J., \& Liberman, R. P. (1980). A review and critique of social skills training with schizophrenic patients. Schizophrenia Bulletin, 6, 42-63.

Zigler, E., \& Phillips, L. (1960). Social effectiveness and symptomatic behaviors. Journal of Abnormal and Social Psychology, 61, 231-232.

Zigler, E., \& Phillips, L. (1961). Social competence outcome in psychiatric disorders._Journal of Abnormal and Social Psychology, 63, 264-271.

Zigler, E., \& Phillips, L. (1962). Social competence and the process-reactive distinction in psychopathology. Journal of Abnormal and Social Psychology, 65, 251-222.

Almir Del Prette, doutor em Psicologia Experimental pela Universidade de São Paulo, é professor no Departamento de Psicologia da Universidade Federal de São Carlos (UFSCar), SP.

Zilda A. P. Del Prette, doutora em Psicologia Experimental pela Universidade de São Paulo, é professora no Departamento de Psicologia da Universidade Federal de São Carlos (UFSCar), SP. Endereço para correspondência: Alameda das Ameixeiras, 60 (Parque Faber); São Carlos, SP: CEP 13570970. Tel.: (16) 272-4230. Fax: (16) 274-8362. E-mail: zdprette@power.ufscar.br 